admitted his preference for an eyeball shrunken to a quarter of its original size as a support for the artificial eye. Sourdille had had a case of sympathetic ophthalmitis after ablation of the anterior segment of the eyeball. In his opinion, exenteration should be reserved for recent wounds. He often inserted a graft of fat under the conjunctiva, sutured en bourse. Dor, in 22 patients who had lost one eye and complained of ocular irritation, found that among these cases the eye had been eviscerated in 21 and enucleated in 1 . On the strength of these figures, he concluded that evisceration was less favourable than enucleation. Vacher thought that too many enucleations were done at the front, and that the cases might well wait some days. Magitot, when operating under unfavourable conditions, undertook in two stages the grafting of cartilage prepared in formol. Even under good conditions, the graft succeeded in only 60 per cent. of the cases. The grafting of a rabbit's eye had yielded Lagrange durable results. Kalt protested against plugging of the orbit after enucleation.

\title{
Ocular Signs of Death
}

Terson described the ocular signs, early and late, of death. The functional state of the pupils was very variable. Light acted slowly upon them for several hours after death, a remark that applied also to atropin and physostigmin. Electricity sometimes contracted the pupil five or six hours after death. As to the ophthalmo-reactions which involved the circulation, even injections of fluorescein did not always colour the human eye in the living. Cauterization, scraping (raclage), applications of copper sulphate, and subconjunctival injections of saline produced no redness in the still warm body, say, two hours after supposed death. Instillations of ether may be dangerous. Terson preferred to apply dionin, and if the application be made two hours after death no reaction followed.

These reactions may be of importance in cases of apparent death before rigidity or decomposition of the body has supervened.

\section{ABSTRACTS}

INJURIES OF THE EYE, ETC., IN WAR

(Second Notice.)

(I) Weekers, L. (Liège). - Night-blindness in soldiers. (Héméralopie chez les soldats.) Arch. d'Ophtal., March-April, I916.

(2) Dantrelle.-Some cases of papillary stasis following war injuries. (De quelques cas de stase papillare consécutive à des blessures de guerre.) Arch. d'Ophtal., May-June, I916. 
(3) Monbrun, A.-Alterations in the cervical sympathetic in war injuries of the eye and orbit. (Alterations du grand sympathique dans les blessures de guerre de l'œil et de l'orbite.) Arch. d'Ophtal., May-June, I916.

(4) Roche, Charles.-Paralysis of the cervical sympathetic in war wounds. (Les paralysies du sympathique cervical dans les blessures de guerre.) Arch. d'Ophtal., NovemberDecember, I916.

(5) Velter, E.-Clinical study of five cases of hemianopsia due to war injuries. (Etude clinique de cinq cas d'hémianopsie par blessure de guerre.) Arch. d'Ophtal., May-June, I9I6.

(6) de Lapersonne, F. (Paris).-War injuries. Injuries of the eye by small fragments. (Blessures de guerre. Plaies de l'œil par petits éclats.) Arch. d'Ophtal., May-June, I9ı6 ; La Clinique Ophthal., December, I916; Trans. Ophthal. Soc. U.K., Vol. XXXVI (1916), p. I42.

(7) Yealland, Lewis R.-Case of gunshot wound involving visual centre, with visual disorientation. Proc. Royal Soc. Medicine, Section of Ophthal., July, I916.

(8) Jessop, W. H. H. (London).-Some ophthalmic lessons of the war. Trans. Ophthal. Soc. U.K., Vol. XXXVI (1916), p. I. and Arch. d'Ophtal., July-August, 1916.

(9) van Schevensteen, A., fils.-Observations regarding factitious conjunctivitis. (Considérations sur les conjonctivites provoquées.) La Clinique Ophtal., October, I9ı6.

(10) Gremeaux, Paul.-Ocular lesions following the action of lacrymatory gases. (Lésions oculaires consécutives à l'action des gaz lacrymogènes.) La Clinique Ophtal., October, 1916, quoting Progrès Médicale (date not given).

(I I) Teulières, M. (Bordeaux), and Valois, G.-The action of asphyxiating or lacrymatory gas on the visual apparatus. (Action des gaz, asphyxiants ou lacrymogènes, sur l'appareil de la vision.) Arch. d'Ophtal., January-February, I9I7.

(12) Frenkel, Henri.-Traumatic subluxation of the crystalline lens. (Sur la subluxation du cristallin d'origine traumatique.) Arch. d'Ophtal., November-December, 1916.

(13) Terrien, F. (Paris).- The repair of lesions of the conjunctiva and eyelids caused by wounds in war. (Réparation des lésions conjonctivales et palpébrales par blessures de guerre.) Arch. d'Ophtal., November-December, 1916.

(14) Sourdille.--Ocular prothesis among those wounded in war. (Prothèse oculaire chez les blessés de guerre.) Arch. d'Ophtal., November-December, 1916. 
(15) Cousin, G.-On forms of sympathetic disease of early onset following injuries received in war. (De quelques formes précoces de réactions sympathiques à la suite des blessures de guerre.) Arch. d'Ophtal., November-December, I9I6.

(16) Harriet.-Traumatic posterior polar cataract. (Cataractes polaires postérieures, d'origine traumatique.) Arch. d'Ophtal., November-December, I916.

(17) Dor (Lyons).-Eight observations on unsuspected intraocular foreign bodies. (Huit observations de corps étrangers intra-oculaires ayant passé inaperçus.) La.Clinique Ophtal., December, 1916.

(18) Cunningham, J. F. (France).-Notes of some war wounds of the eye and orbit. Trans. Ophth. Soc. U.K., Vol. XXXVI (1916), p. 147.

(19) Frenkel, Henri.-On folding of the retina in circles by contusion of the posterior segment (lesions of the retina by windage). (Sur le plissement en cercles de la rétine par contusion du segment postérieur [lésions de la rétine par "vent du boulet."]) Ann. d'Ocul., T. CLIV, January, I9I7.

(20) Morax, V. (Paris).-Glaucoma secondary to wounds of the eye with intra-ocular foreign bodies. (Glaucome secondaire aux blessures du globe avec éclats intra-oculaires.) Ann. d'Ocul., T. CLIV, January, I9I7.

(21) Rollet (Lyons) and Velter.-Choroido-retinal lesions resulting from wounds in war. (Lésions chorio-rétiniennes par blessures de guerre.) Arch. d'Ophtal., January-February, 1917.

(22) Ourgaud.-Destruction of a portion of the cornea in its whole thickness; restoration by conjunctival flap. (Large perte de substance de la cornée comprenant toute son épaisseur. Restauration par recouvrement conjonctival.) Arch. d'Ophtal., January-February, I9I 7.

(1) Weekers has been struck by the large number of cases of night-blindness he has met with in the Army. In January of 1915 the number of cases sent for ophthalmic examination was 95 out of a total of 496 patients, or over 19 per cent. All cases in which there was definite ocular lesion, such as retinitis pigmentosa, are excluded, and, with the exception of a rather large number of errors of refraction there was nothing local to account for the affection. The patients were in good health and well-nourished. The author believes he was able to exclude malingering; in fact some of the cases were officers who were very anxious lest their defect should interfere with promotion. 
Weekers draws the following conclusions :-

1. Night-blindness is frequent among soldiers. It is met with in 10 per cent. of the cases sent for ophthalmic consultation.

2. Cases of night-blindness are particularly numerous in the winter months, when the nights are long.

3. Numerous cases of refractive errors are found among these patients.

4. Many of these soldiers suffered from similar trouble before the war (congenital night-blindness). Night-blindness can be produced by the conditions of trench life (acquired night-blindness). These same conditions may aggravate a congenital night-blindness.

5. The development of night-blindness is provoked by many factors of unequal importance. In the first place it is necessary to cite the abnormal character of trench life, which is above all nocturnal, the fatigue, the continual nervous shock, and the moral unrest leading to a greater or less degree of asthenia. The ocular fatigue resulting from refractive error is equally a very important factor. The uniformity of diet and use of preserved food may also play a part.

6. Treatment must be devoted to the cause. One of the most efficacious means of relieving the symptoms is the exact correction of refractive anomalies and particularly astigmatism. The use of smoked glasses during the day as a preventive of dazzling is an excellent adjuvant. A varied diet and rest, so far as military necessities will allow, should be ordered.

7. The prognosis is good. In spite of the complaints of the sufferers they can be kept at the front, with some special arrangements in the more marked cases.

E. E. H.

(2) Dantrelle has collected three interesting cases of papillœdema.

The first man was wounded in October by a shell fragment. Fragments of shell and bone were removed, and lumbar puncture was done several times. The man was sent back as cured, but referred to Dantrelle on account of visual trouble. He was found to have papillœedema on both sides, slightly more marked on the left. $\mathrm{He}$ suffered from obscurations of vision, lasting from two to ten minutes, and accompanied by vertigo and sweating. At other times his vision was practically normal. Radiography revealed one large and two small intracranial fragments of shell.

The second man was injured in the head by a bullet. Five months after, he suffered from meningeal symptoms with fever, which were thought to be due to tuberculous meningitis. Cerebro-spinal fluid, under pressure, contained a considerable quantity of albumen, and $0.65 \mathrm{gm}$. of sugar per litre. No tubercle bacilli were found, and inoculation of a guinea-pig was negative. He was trephined, and recovered. When seen by Dantrelle, he had a depressed and pulsating scar in the right superior frontal region. From time to time, what was 
practically a cerebral hernia appeared in the scar, accompanied by severe headache and obscuration of vision. Papillary stasis marked and equal on both sides; vision normal. Radiography showed a bullet lying with its long axis transverse and horizontal in front of the chiasma, on the inferior face of the right frontal lobe.

The third patient was wounded in the lung by a bullet. As he fell he received a second blow on the head. He was not picked up for 36 hours. He suffered a good deal from severe headache, and some time later, when scratching the scar on his head, he detached a piece of shell. He. was sent back to duty, and came under observation when trying to obtain a correction for his presbyopia. He had a pronounced typical papillodema, somewhat more marked on the left side. The visual fields were slightly contracted, and the blind spot was enlarged. Lumbar puncture showed that the cerebro-spinal fluid was under pressure, and contained $1 \mathrm{gm}$. of sugar per litre. An intracranial fragment of shell was found by radiography. The patient refused further treatment. Nevertheless, the swelling gradually diminished and the vision remained normal.

These are the only three cases of papilloedema that Dantrelle has found among a large number of head injuries. He considers that in most of the cases of intracranial injury with retention of fragments, there exists such a large breach in the bony. skull as to render the mechanical production of hypertension practically impossible.

\section{E. E. $\mathrm{H}$.}

(3) Under this heading Monbrun has collected five cases, all of which had suffered from ruptured globe due to some projectile and which also had remaining a stump consisting of either of the back part of the eye due to imperfect enucleation or exenteration, or else a shrunken globe. In none was there any sign of inflammation about the stump, which was soundly healed. Symptoms did not appear till from three to fifteen months after the injury. The symptoms found consisted of severe burning pain, constantly present, radiating to the vertex and occipital regions. One of the sufferers had a region of cutaneous hyperæsthesia at the vertex with a sensation of twitching and pain (tiraillement), similar to that caused by the passage of an electric current. He also had a similar sensation at the level of the lower part of the thorax and epigastric regions.

All the patients presented considerable mental weakness. In addition to the constant sensation of heat, there was present redness of the face and ears, either complete or more or less limited to one side, together with sweating in the region affected with pain and redness. The least effort provoked exacerbation of all the symptoms.

In explaining these symptoms Monbrun quotes the work of other surgeons on similar symptoms observed in other parts of the body, 
believed to be due to a neuritis of the sympathetic. Acting on this supposition, he removed the stump from two of his patients, but without benefit.

E. E. H.

(4) Claude Bernard, in 1858, and Horner, in 1861, wrote upon paralysis of the sympathetic; the former from experimental investigation, the latter from clinical observation. Hence the signs and symptoms of paralysis of the cervical sympathetic are known as the Claude Bernard-Horner syndrome.

Roche has collected records of 11 cases of paralysis of the cervical sympathetic following wounds received in war. Of these, 4 were under his own observation and hitherto unpublished. $\mathrm{He}$ has analysed the cases and gives a tabular statement showing which of the signs of sympathetic paralysis were present in each case. These signs are miosis, ptosis, enophthalmos, ocular hypotony, secretory disturbance, vasomotor disturbance.

It is interesting to note that not one of the 11 cases showed the complete syndrome. Miosis was present in every case; ptosis in 4 ; enophthalmos in 10 ; vasomotor disturbance in 6 . In no case was the ocular pressure lowered.

The facts as to the nature and site of the wounds are briefly narrated below. The author points out that it is impossible to state with any certainty which ganglion or which branches of the sympathetic have been wounded. $\mathrm{He}$ suggests that the variation in the clinical features may bear a definite relation to the locality of the injury to the nervous chain.

CASE 1.-Wound by fragment of shell ; cicatrix in front of left deltoid, near coracoid process; foreign body close to first costovertebral articulation.

CASE 2.-Wound of entry of bullet in middle of left malar region; wound of exit in nape of neck at level of fifth vertebra.

CASE 3.- -Wound by fragment of shell, which entered the right carotid region, lacerating the sterno-mastoid. Fragment found among the cervical spinous processes and removed.

CASE 4.- Shell wound, the fragment entering in right lateral cervical region behind the sterno-mastoid. Fragment localized $1 \mathrm{~cm}$. in front of the transverse process of the sixth vertebra.

CASE 5.- Shell wound; foreign body shown by X-rays close to the sixth cervical vertebra on the right side; a fragment of bone projecting into the medullary canal and pressing on the cord; in addition to the sympathetic paralysis, R. choked disc. Removal of the foreign body was followed by disappearance of the paralytic signs, and recovery of vision.

CASE 6.-Wound by fragment of shell $2 \mathrm{~cm}$. behind and above the tip of the left mastoid; three fragments lodged under the left malar bone. 
CASE 7.-Shell wound by several fragments; the largest lodged in right lateral cervical region.

CASE 8.-Bullet entered the right side of neck, perforated the sterno-mastoid near the clavicle, and lodged close to the eighth dorsal vertebra.

CASE 9.-Shrapnel bullet, entered at the posterior margin of the sterno-mastoid, $5 \mathrm{~cm}$. from the mastoid process, penetrated the larynx and was expelled by coughing.

CASE 10.- Shell wound; the projectile entered right parotid region, and came out at the base of the skull posteriorly, close to the middle line.

CASE 11.-Wound by a fragment of shell in the right preauricular region, at the origin of the ascending ramus of the maxilla.

Roche points out that the usual explanation of the action of cocaine, as due to stimulation of the dilatator pupillæ fibres, is not consistent with the generally paralysing action of the drug. He prefers to explain its action as producing a paresis of the sphincter which, in normal conditions, allows the dilatator fibres to act, but that these latter fail to do so after destruction of the sympathetic. The probable seat of the lesion varies from the first to the sixth cervical ganglion, but the eye symptoms did not show any particular difference to correspond with the difference of level.

J. B. LAWFORD.

(5) Velter adds five more cases of hemianopsia to those already published resulting from war injury:

Case I had a very extensive lesion of the occipital lobe which presumably affected the optic radiations and cortical centre and resulted in a permanent homonymous right hemianopsia with preservation of macular vision.

Case II, also an extensive injury, when first seen had only telescopic vision. This first improved to a left homonymous hemianopsia, and, finally, to an homonymous defect limited to the left inferior quadrant. Velter considers that this was a partial lesion of the occipital lobe affecting the superior bundles of the optic radiations, or the superior lip of the calcarine fissure. The early double hemianopsia was probably due to contusion of the brain and pressure by clots.

Case III. The injury, which was due to a rifle ball fired at close range, involved the left lateral sinus. The projectile had rebounded and lodged in the left trapezius muscle. The visual fields at first were confined to central vision, improving to inferior horizontal hemianopsia, and, finally, to hemiachromatopsia in the right inferior quadrant. Velter considers that in spite of the extensive nature of the superficial injury, the encephalic lesion had been very slight, involving only the superior lip of the calcarine fissure. The earlier typical horizontal hemianopsia must have been due to a hæmorrhage situated between the cerebral hemispheres. 
Case IV. Lesion less extensive. Total blindness for five hours, then homonymous right hemianopia which gradually became less, leaving a marked contraction of the colour fields but without any inversion.

Case $\mathrm{V}$ was that of a medical man who was injured by a shell fragment, which did not penetrate. Radiography showed irregularity of inner table with what looked like a sharp fragment in the neighbourhood of the cuneus. The visual fields showed a scotoma, absolute and symmetrical in the right superior quadrant of the macula. As in the similar cases described by Marie and Chatelin (Revue Neurologique, 1915, p. 882), the lesion in this case was very small, probably a simple puncture of the extreme point of the occipital lobe. Velter points out how these cases support the hypothesis of the localisation of macular projection to the posterior point of the occipital lobe. Reproductions of fields and photographs of the scars of the injuries accompany the paper.

E. E. H.

(6) The wounds dealt with by de Lapersonne were inflicted with fragments of bombs, hand grenades, steel and nickel casing of bullets, copper fragments, morsels of earth, stone, and wood, and so forth. He speaks only of perforating wounds of the cornea or sclera with a wound of entry often scarcely visible. Of these injuries he had had among 1,000 wounded soldiers 191 under care. The wounds often give rise to very serious complications. Thus, among 191 cases, in $36^{\circ} 65$ per cent. there were traumatic cataracts, with preservation of vision from $2 / 3$ to $1 / 20$; in 16.23 per cent. there was slight irido-cyclitis, with vision from $2 / 3$ to $1 / 20$; and in $47 \cdot 12$ per cent. there was complete loss of the eye from irido-cyclitis. The corneal wounds were rarely clean-cut, as in industrial injuries, and it was sometimes difficult to decide whether one or more perforations were present. They were often complicated by prolapse of the iris, lens, or organized vitreous. In perforating scleral wounds the points of entry might be concealed by chemosis or conjunctival injection, and diagnosis was made by the diminished intra-ocular pressure and by the loss of the contents of the anterior chamber. The intra-ocular lesions seen by de Lapersonne comprised: (1) hyphæma with tearing of the pupillary border of the iris, and hernia of the iris ; (2) every variety of traumatic cataract. The presence of foreign bodies was frequent. The electro-magnet was useful only in the case of a magnetic foreign body. Radiography and radioscopy, however, were useful, even if the foreign body was not magnetic. Exact localization was generally difficult in the case of a non-magnetic body, and for war wounds was not very useful. de Lapersonne directs attention to the danger involved by the explosion of a projectile near the eye. Small penetrating wounds were produced, which became complicated with irido-cyclitis, and even threatened with sympathetic ophthalmitis. 
Since the beginning of the war, de Lapersonne has not met with a single case of sympathetic ophthalmitis, and this is attributed to asepsis and better antisepsis, and there is also the fact that enucleation is more often performed when the first eye is lost or useless. Although the author has not met with definite sympathetic ophthalmitis in a sound eye, he has seen many cases where the two eyes being affected, irido-cyclitis occurs in the eye less affected, even if there has not been perforation.

Finally, the author has something to say about the means adopted for protecting the eye from wounds by small foreign bodies. $\mathrm{He}$ mentions the Adrian helmet, the masks and the cagoules with mica or cellophane spectacles, and the stereoscopic spectacles devised by Terrien and Lacan. These contrivances are tiresome for shooting with, and as they diminish luminosity, they cannot be employed at night. In de Lapersonne's opinion, the spectacles with more or less solid wire grating, lined with a leaf of cellophane, are the best; they can be worn like motor goggles, and are vapour-tight enough to keep off lacrymatory gas.

S. S.

(7) Yealland reports the following case: After a perforated bullet wound of the skull, a soldier, aged 31 years, developed several nervous signs and symptoms, such as right hemiplegia, left hemianopia, contraction of the visual fields, and some. degree of apraxia. Visual disorientation was also present, so that the patient could not tell the relation of objects in space. An object lying to his left usually appeared to be nearer to him than one to his right. It was believed that the whole visuo-sensory cortex on the right side had been destroyed by the injury.

S. S.

(8) See The British Journal of Ophthalmology, No. 2, p. 121.

(9) The article by van Schevensteen, of the Belgian Army, is of great interest, dealing, as it does, with a form of malingering which apparently must be rather common. The author refers to two types, namely : (1) where the provocative agent is ipecacuanha powder, and (2) where the agent cannot be exactly identified. In the former case the symptoms are due to the action of the alkaloid emetine. This produces two forms of conjunctivitis, according to whether the powder is introduced once or repeatedly. That is, it causes either an acute or a chronic conjunctivitis. One gathers from what the author says, that after a little experience, one cannot mistake these forms of conjunctivitis for others caused by pathogenic organisms.

In the acute forms there is often a unilateral conjunctivitis which begins suddenly, with violent irritation from the very start. There is considerable swelling of the conjunctiva of the 
turgid lower cul-de-sac. Secretion is minimal, sometimes forming a pseudo-membranous layer. The eyelids cannot be opened spontaneously. The surrounding parts have an erysipelatous appearance.

In the chronic forms the unilateral type is frequent, the lesion is confined to the lower cul-de-sac. The conjunctiva is smooth, with deep folds, and the vascular tracery is lost. This smooth conjunctiva has a peculiar salmon tint. Sometimes the upper palpebral conjunctiva is involved. Secretion is minimal. The bulbar conjunctiva has a peculiar propensity to redden on handling the eye and on the employment of every kind of collyrium. The history, the unlikely causes invoked for the affection, its course and long duration, and its resistance to all kinds of treatment are all points which should not be neglected, while, finally, the clinical diagnosis may be corroborated by the discovery of ipecacuanha. By special methods ipecacuanha may be found microscopically, but the author says the diagnosis is so clear clinically that this is not necessary.

The differential diagnosis from blennorrhœal conjunctivitis, trachoma, and diphtheritic conjunctivitis is then gone over in detail. Regarding the first, the principal point is the absence of the gonococcus from the conjunctiva and urethra. As to trachoma, it apparently occasionally happens that something resembling trachoma follicles may be seen at the upper border of the tarsus, but the application of an occlusive collodion-fixed dressing results in their disappearance. The resemblance to diphtheritic conjunctivitis can be brushed aside. The false membrane is quite different and there are none of the usual symptoms, nor swelling of the preauricular gland. Similar considerations apply to Parinaud's conjunctivitis and to the streptococcic variety. If there is ever a slight doubt regarding other kinds of catarrhal conjunctivitis just at the onset, the course taken by ipecacuanha conjunctivitis, its peculiar lesions, and especially the salmon tint of the lower conjunctiva are characteristic. Treatment is easy and essentially consists in getting rid of the use of ipecacuanha. For the acute initial symptoms, an antiseptic dressing, and a little atropine should there be a corneal lesion. The collodion-fixed dressing has given the author excellent results where either ipecacuanha or other agents for the production of conjunctivitis are in question. This is left in place for several days, when the symptoms are found to have disappeared.

Besides ipecacuanha other chemical agents may produce just as strange forms of conjunctival inflammation, but of these, such as podophyllin, jequirity, cantharides, and chrysarobin, the author has not had special experience. All his cases of this type have been caused by ipecacuanha.

Regarding the author's second heading, cases, that is, in which the causative agent cannot be exactly ascertained, he suggests the 
different points in the diagnosis from a spontaneously caused condition. These points are: (1) bilaterality is usual, (2) chronicity, torpidity and resistance to treatment, (3) lividity of the cul-de-sac, and sometimes pseudo-follicles at the upper border of the tarsus, (4) "paradoxical" secretion, i.e., plenty of secretion at the usual morning visit, but very little if a surprise visit is made and (5) anomalous and uncertain causes offered in explanation of the symptoms. Among the agents of such anomalous forms of conjunctivitis may be mentioned soä, tobacco powder and juice, pepper, tartar from the teeth, and other strange and often dirty things.

ERNEST THOMSON.

(10) The conclusions come to by Gremeaux, of the French Army, are as follow:-

The lacrymatory gases employed up to now by the Germans cause ocular troubles, which are confined to a more or less violent conjunctival reaction, always accompanied by exfoliation of the limbal corneal tissue. These lesions rapidly attain their maximum extent, and when the wounded individual can be attended to soon afterwards, they remain quite limited and progress towards cure under appropriate treatment. For a given strength of gas the time of exposure of the eyes to it seems to have no influence whatever, either as regards the intensity of the symptoms or the ultimate course. The intense lacrymation determined by the action of lacrymatory gas, on the one hand, and the occlusive palpebral reflex, on the other hand, seem to account sufficiently for the foregoing facts, in that the eye is thus mechanically protected.

The treatment of these cases is as follows: - The occlusive bandage must not be worn. Mild lotions to be used. The pupil to be kept dilated, watching the tension. Every second day 1 per cent. zinc sulphate to be instilled. Potato starch poultices in frequency according to the intensity of the hyperæmia. A "floating" bandage to protect from light, while leaving the eye uncovered. No cocaine, of any degree of dilution whatever, is to be employed, as the epithelium is already rendered friable by the action of the gas.

\section{ERNEST THOMSON.}

(11) Teulières and Valois, who are in charge of the Ophthalmic Centre of the 13th Military Area, receive their patients two to three days after their exposure to gas attacks. They believe this explains their inability to establish any differences between the effects of gas projected in clouds from the enemy lines and of that set free by the bursting of "lacrymatory" shells.

The subjective symptoms are constant, and are those common to all cases of violent irritation of the conjunctiva, very severe smarting and pricking sensations, blepharospasm and photophobia. These symptoms last for a considerable time. In a large number of the cases, when this first phase of irritation has passed and the eyes can 
be opened, the visual acuity has been found considerably reduced; but in no instance has restriction of, or scotomata in, the field, or dyschromatopsia been observed.

The following lesions have been noted :-

Eyelids.-Burns of the lid margins caused by the gas and aggravated by the incessant flow of tears, macerating the raw surface. Oedema of lids.

Lacrymal apparatus.-Lacrymation, often excessive, but unaccompanied by other lesions.

Conjunctiva.-Congestion of this membrane, most noticeable near the limbus; slight chemosis.

Iris.-The changes in this structure are noteworthy. Most frequently the colour is modified, becoming less vivid; the surface has a flocculent (tomenteux) appearance. The pupil reacts sluggishly to light, and slowly to mydriatics; several applications of atropine are necessary to produce dilatation. This paretic condition of the iris is generally long continued. These changes are indicative of severe congestion of the iris; posterior synechiæ have not been observed.

Posterior segment of the eye.-No disturbance in the transparent media has been noted.

The lesions of the deeper parts are limited to the optic disc and the retina. A mild degree of neuro-retinitis is present in many cases. The papilla is blurred, with ill-defined margins; sometimes there is slight loss of colour, especially noticeable in the temporal part.

Around the disc the retina undergoes a peculiar but always similar change, becoming slate-coloured. This alteration in colour is thought to be due to odema; it is not limited to the immediate vicinity of the disc, but extends along the large retinal vessels. The retinal veins are dilated, and often tortuous; the calibre of the arteries is unaltered.

These signs are always coincident with diminution of visual acuity, the loss in one case reaching $8 / 10$.

The authors discuss the ætiology of these neuro-retinal lesions; they are not satisfied with the suggestion that the deeper lesions are merely an extension of the congestion phenomena noted in the anterior parts of the eye. Their view is rather that the inhalation of these noxious gases induces a severe reaction in the mucous membranes of the nasal cavities and of all the accessory sinuses, and that by this path and the cribriform lamina of the ethmoid the meninges of the optic nerves may be directly involved.

In all the cases, save one, under the observation of the writers, complete recovery ensued. In the exceptional case, after the neuroretinal changes had disappeared, vision in each eye was only 0.3 at the time the patient was discharged from hospital. 
The authors' experience of these "gassed" patients justifies a wholly favourable prognosis.

J. B. LAWFORD.

(12) Frenkel is of opinion that subluxation of the lens as a result of injury is much more common than is generally supposed. He groups cases under two headings: (a) typical cases, in the diagnosis of which there is uncertainty; (b) atypical cases, difficult to diagnose, and in which the following are the most valuable signs :-

(1) The existence of a fold in the iris concentric with the circulus arteriosus major, and limited to a portion of the circumference. This fold is shown by a single (sometimes double) line produced by the close apposition of the iris to the edge of the subluxated lens ; (2) diminution of the pupillary reflexes, and partial mydriasis ; (3) corectopia : this, if bilateral, is usually congenital, if unilateral, is almost always acquired; (4) minute tears in the iris, near the root, or in the sphincter area: they are frequently so small as to be easily overlooked; (5) retroversion of the iris at the free edge of an irido-dialysis; (6) partial traumatic cataract; and (7) acquired myopia or hypermetropia.

Three varieties of subluxation are described: $(a)$ with rotation of the lens on an equatorial axis; $(b)$ with displacement of the lens backwards; $(c)$ with displacement forwards. The third variety $(c)$ is that most frequently overlooked.

The proportion of cases of subluxation among the wounded at the Ophthalmic Centre of Toulouse was, in 1915, two per cent. in a total of 547 ; in 1916, seven per cent. in a total of 518.

J. B. LAWFORD.

(13) Apart from its intrinsic interest, this paper by Terrien merits notice as a contribution based on a large war experience of wounds of the eyelids and orbit, for the repair of which plastic operations were undertaken. It is a paper which unfortunately does not lend itself to review. Only one case is described, and that briefly, in which a plastic operation restored an upper lid almost completely destroyed by shell wound and enabled the patient to wear an artificial eye.

In the rest of the paper the writer discusses the merits of the varieties of flap which he has employed; the sliding flap, the flap with pedicle, and cutaneous and conjunctival grafts. He seems to favour the use of pedunculated flaps from the immediate vicinity of the eyelids, whenever possible; but in cases of extensive wounds or cicatrices for which large flaps are necessary, he has had recourse to the Italian method, and has taken a flap from the arm, liberating it from its pedicle about the twelfth day.

For cases of total symblepharon he has employed skin grafts; these he has taken from situations where the skin is thin, e.g., the 
inner surface of the arm, or behind the ear; they should be free from subcutaneous cellular tissue. The adherent lid having been detached in its whole length and breadth from the orbital cavity (presumably he refers to cases in which the globe has been destroyed) and a cul-de-sac constructed, the flap, measuring about one quarter more than the prepared area, is sutured into place, care being observed to obtain the most accurate co-aptation possible. The stitches are removed from the sixth to the eighth day, and an artificial eye is inserted about the third week.

The author has some fear of late shrinking of these flaps, and, when possible, gives preference in such cases to a pedicle-flap taken from the temporal region.

J. B. LAWFORD.

(14) The vast number of cases of wounds of the eyeball and adjoining structures, among the fighting forces, has provided ample opportunity to Sourdille to evolve operative methods by which a satisfactory ocular prothesis may be obtained. He divides his cases into: (1) those in which the wound is limited to the eyeball ; (2) those in which the injury to the eye is complicated by palpebroconjunctival or orbital lesions.

In the first group he advises exenteration, if it can be done not later than the third or fourth day after the wound. In the men reaching the base hospital the wounded eye, in many instances, is already attacked by irido-cyclitis, and in some contains a foreign body. These eyes are unsuitable for any operation, except enucleation.

The author is dissatisfied with the prothesis obtainable after simple excision of the globe, and has therefore devised and practised an operation which he calls "plastic enucleation," and which has so far, especially in his later cases, given a very satisfactory result. $\mathrm{He}$ has, in all his nine cases, employed general anæsthesia. The steps of the procedure are as follows:-

1. The conjunctiva is divided at the limbus and dissected up as far as the recti tendons.

2. Each rectus tendon is seized by forceps, and cut through at its attachment ; a silk suture (on two curved needles) is passed through the tendon and the conjunctiva over it. These threads are secured in a clamp forceps.

3. The globe is removed, and a plug soaked in dioxide is inserted into the cavity and light pressure applied to arrest hæmorrhage.

4. A circular piece of skin, 28 to $30 \mathrm{~mm}$. in diameter, and including a thin layer of fat, is taken from the buttock.

5. This graft is introduced into Tenon's capsule and fixed by the threads already in the recti tendons. Additional stitches between these attach the conjunctiva to the graft.

6. A light compressive bandage is applied. The stitches are removed on the seventh or eighth day. 
The resulting stump is resistent, sufficiently prominent, and very mobile.

Cases in the second group, in which there is damage to or destruction of the eyelids, or portions of the orbital margin of wall, will often tax the skill and ingenuity of the surgeon to the utmost. No definite line of treatment can be laid down. Plastic operations, frequently repeated, may be necessary and in many instances months may elapse before the final result is attained. In some cases where the malar bone or outer wall of the orbit has been destroyed, the author has made use of bony grafts taken from the surface of the external malleolus. He urges that surgeons at the front should devote greater care to the early treatment of wounds, lacerations, and displacements of the periorbital tissues; such lesions, if neglected in the early stage, lead to deformities which, in the cicatricial stage, may be almost irremediable.

\section{J. B. LAWFORD.}

(15) Cousin, in common with other surgeons, holds that there exists a group of signs, which cannot be accurately described as sympathetic ophthalmitis, but which should be carefully differentiated from "sympathetic irritation." $\mathrm{He}$ would place cases presenting these signs in a category apart from those of true sympathetic inflammation and those of sympathetic irritation. Examples of this "sympathetic reaction," as the writer terms it, have occurred not infrequently among the wounded of the French Army.

In the wounded eye the symptoms are pain, tenderness on pressure, lacrymation, conjunctival injection. Photophobia is a less constant symptom. These symptoms date usually from the time of the injury, which in most cases is a perforating wound, and persist after cicatrisation is complete. The pain is usually persistent, although not severe, and is occasionally liable to short exacerbations. Pain and tenderness have never been absent from the cases under the author's observation. Lacrymation and conjunctival injection vary greatly in degree.

In the unwounded eye, the symptoms present considerable resemblance to those already described, but are, as a rule, less marked. Their onset is later; in some instances 36 to 48 hours, but more commonly seven to ten days after the injury.

The writer mentions four symptoms as characteristic: photophobia, lacrymation, discomfort in reading, slight lowering of visual acuity. Photophobia is the most frequent symptom, and is usually well-marked, but relieved by the use of tinted glasses. Lacrymation is of very variable intensity. Discomfort induced by reading, or by any occupation requiring accurate and prolonged use of the eye, is often the symptom which leads the patient to seek advice.

The loss in visual acuity, always slight, is difficult to estimate accurately ; in most cases no record of the vision before the accident 
is obtainable. Cousin states that he has found a reduction in acuity varying from $1 / 10$ to $5 / 10$. Ophthalmoscopic signs are negative; pain is absent.

These symptoms, while resistent to ameliorative treatment, all disappear shortly after removal of the wounded eye; the defect in vision being the most tardy. Enucleation of the wounded eye is the treatment recommended. Notes of eight cases are included in the paper.

J. B. LAWFORD.

(16) The author describes in detail two cases of unilateral posterior polar cataract in soldiers, following the explosion of a shell a few metres from them. The two men were close together at the time. They were examined by Harriet nine days later. In each patient there was no sign of wound of the eyeball ; in one there was a small superficial scar at the lower border of the orbit near the nose ; in the other there was no evidence of wound of the face or head. The men were knocked over by the explosion, and said that they felt as if the injured eye had been severely scalded.

In each case there was persistent traumatic mydriasis, and a stellate opacity at the posterior pole of the lens; at a later date the lens became opaque throughout in both patients.

Harriet publishes these cases as examples of cataract caused by the shock of the explosion, i.e., by the impact of aerial waves. The absence of all evidence as to the conditions present immediately, or shortly, after the injury, renders it difficult to accept his view of the ætiology as the most probable.

J. B. LAWFORD.

(17) Dor, now stationed at Nancy, reports the details of eight cases, out of a total of about thirty seen by him during six months, in which the foreign body had not been diagnosed. In two of them vision could have been preserved if the diagnosis had been made. It is curious that four of these cases had been examined by specialists, and, more than that, one of them had been seen by three, and another by no fewer than five specialists. The only comment Dor makes, apart from the hint that the foreign bodies ought to have been diagnosed, is that the mistake is only possible when the foreign body has passed through the sclera, since wounds of this membrane close in two or three days and leave only the most trifling cicatrices.

ERNEST THOMSON.

(19) In the present illustrated article, Frenkel submits a somewhat unique clinical picture which he has come across in the course of his military medical work, and which he ventures to attribute to the effects of windage. He quite realises the difficulty that exists in establishing the diagnosis of such cases, for one must take care not to attribute to windage any case in which a more solid body may have been operative. The present case, moreover, is certainly 
less convincing by the facts, first, that the Wassermann blood reaction had been found positive nearly eleven months before Frenkel examined the case; and, secondly, that Frenkel did not

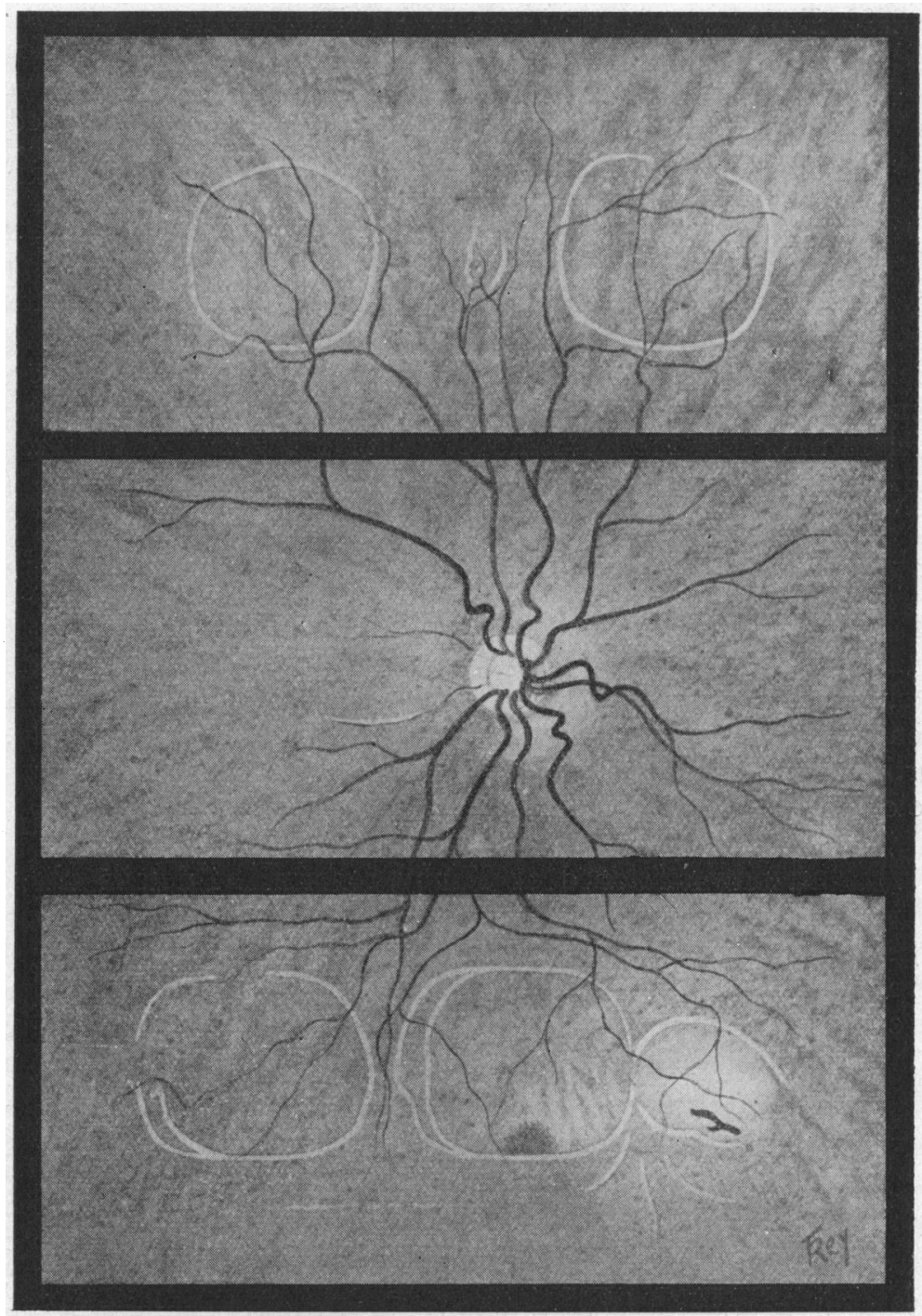

see the patient until nineteen months after the date of the alleged injury.

On February 17, 1915, a sergeant of infantry was buried as a result of successive burstings of many " tear" shells, a particular shell having burst on the parapet about two metres in front of him. Although "blinded" by the gas and the [dust, he could still 
distinguish objects when extricated, and was able to keep on duty, and did so till September 14, 1915, when he reported a dimness of sight in the right eye as having been noticed almost at once after the shell-burst on February 17. By various stages he reached Rouen on October 8, 1915, where the diagnosis was made of "unequal pupils and optic neuritis." On October 28 the left eye was noted as normal, while the right showed vitreous opacities with exudates and foci of choroido-retinitis in the lower part of retina. Wassermann +; treatment by iodide of mercury. By November 29 he had had sixteen injections, and a few days later could tell the form of the hand. It was not till September 14, 1916, that Frenkel saw the case, when he noted that there was no sign of external wound, no lesion or affection of the cranial nerves, and that hearing was normal. The right eye was slightly divergent, and the pupil reacted to light, feebly directly, but normally consensually; pupils equal; media clear. Peculiar fundus appearances, shown in Figure, as follows.-Right optic disc has kept its rosy hue, except the temporal sector, which is slightly greyish; all the retina above papilla seems raised, but its colour is quite normal and rosy, the upper arteries appearing to be raised with the retina ; in the lower macular region is seen a whitish line, parallel to the inferior temporal artery, concave upwards, having the form of the arc of an ellipse, length two disc diameters, with a reddish reflex on the convex side; macula apparently normal. At the periphery of the retina special changes: (a) in the upper-outer quadrant a white line, definitely circular, of retinal folding, diameter, judged from the drawing, about two-and-a-half times that of the disc, enclosing normal retina save for four or five whitish dots at the upper part ; (b) in lower-outer quadrant a rather larger similar area, only rather more oval than circular; (c) in lower portion of retina another ovoid area, with a partly resolved hæmorrhage at its lower part and some whitish discolouration of retina; (d) below and to inner side another, incomplete, ovoid area, with a hæmorrhage near its lower edge, close to arterial twigs; (e) in the upper-inner quadrant another ovoid area without hæmorrhage, but with three whitish flecks due to resolved hæmorrhage: (f) the three lower areas are contiguous, while between the two upper ones is a suggestion of a small ovoid area with a whitish tick in its centre. R.V.= fingers at $30 \mathrm{~cm}$., colour perception absent, field of vision from fusion of peripheral and central scotomata, has the form of a horse-shoe concave next the centre, extending from 30 to 40 degrees, in which belt white is perceived but not colours. Left eye : normal vision, colour perception, and field.

Frenkel says the interpretation of the peculiar fundus appearances does not appear to. present any difficulties. His view of the case is that the displacement of air by the bursting, only two metres away, 
of the shell, had been enough to compress the right eyeball backwards into the orbit, the left eye, as he says, having probably been out of the sphere of action of the air waves. The right eyeball thus came violently in contact at five points, two above and three below, with the bony orbit, the disposition of the orbital walls allowing one to accept five points of contact between globe and bony surfaces. The slope of the bony walls has caused the areas to be oval and not circular, as they would have been otherwise. When the air pressure eased off, the dimpled-in sclerotic recovered, but the retina, folded or crinkled at the edges of the scleral depressions, retained the appearances noted by the ophthalmoscope. Frenkel argues against its being direct concussion from earth, and holds that to produce these unique fundus changes any force must be instantaneous, of short duration and great intensity-conditions more likely to be got from air than from earth pressure.

Frenkel refers to cases from the literature of retinal hæmorrhages, vitreous hæmorrhages, retinal detachment, lens dislocation, serous choroiditis with secondary glaucoma, progressive myopia with macular choroido-retinitis, and that unconvincing group of the psycho-neuroses with blindness-all attributed to windage.

The article is furnished with a drawing of the fundus (reproduced in this abstract), charts of the fields, and a diagram to show the five points of pressure in the orbital walls.

No mention is made of the degree of prominence of the retina within the several areas, as estimated by the ophthalmoscope, nor is any explanation vouchsafed for the very defective central vision in the right eye.

W. C. Souter.

(20) Morax considers that he is dealing here with a definite clinical entity, for although he had seen but one case of this sort in civil practice, and that a case of siderosis, he has met with five cases amongst a thousand wounded in the present war. He puts on one side cases of glaucoma secondary to irido-cyclitis after perforating injuries, with or without an intra-ocular foreign body, cases of glaucoma secondary to the rapid development of a traumatic cataract, or to a contusion of the globe with dislocation of the lens. In his cases there has been an extremely fine penetration through sclera alone, or through cornea, iris, and lens, with greater or less involvement of vision. The presence of the foreign body may or may not have been recognized. The early reaction has long subsided, and it may be many weeks or months after the wounding when fresh developments cause attention to be directed to the eye. The cases may be acute, subacute, or chronic as regards their increased tension. Very few such cases are to be met with in the literature. In most of Morax's cases the entrance wound has been very slight, and might easily have been missed. The foreign body has been 
INJURIES TO THE EYE, ETC., IN WAR

\begin{tabular}{|c|c|c|c|c|c|c|c|c|}
\hline 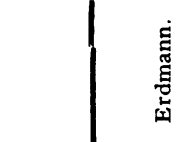 & 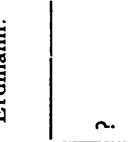 & 。ี & n. & 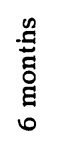 & 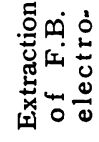 & & 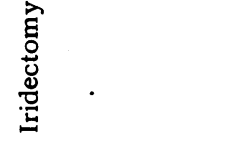 & $\underset{\substack{n \\
\infty}}{\stackrel{m}{N}}$ \\
\hline 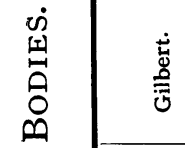 & $\hat{f}$ & 总 & n. & 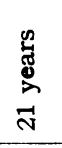 & 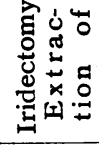 & & 莺. & 1 \\
\hline 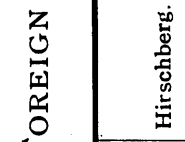 & : & 몹 & 总 & 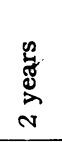 & 1 & 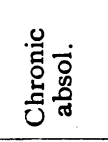 & 兽 & 1 \\
\hline 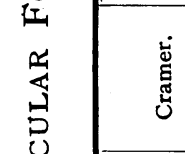 & $\stackrel{\infty}{m}$ & 苂 & 㤩 & 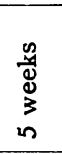 & 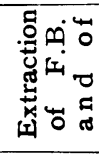 & 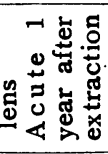 & 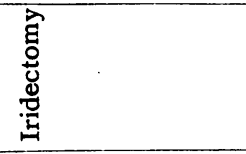 & $\stackrel{0}{\stackrel{0}{1}}$ \\
\hline 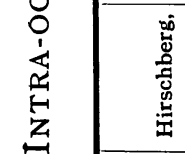 & n. & 。ี & n. & 营 & 1 & 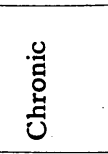 & 离 & 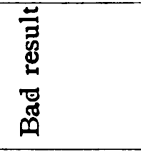 \\
\hline 怤 & $\vec{m}$ & . & $\stackrel{\substack{\dot{q} \\
\dot{u}}}{\dot{0}}$ & 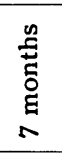 & 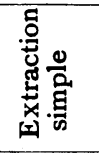 & $\begin{array}{l}0 \\
0 \\
0 \\
0\end{array}$ & $\underset{0}{\dot{0}}$ & 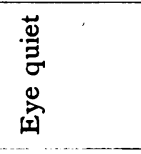 \\
\hline 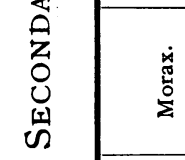 & 요 & n. & ก. & 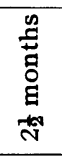 & 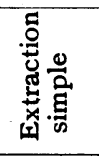 & 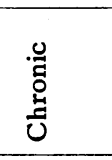 & 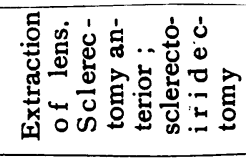 & 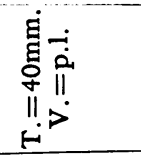 \\
\hline 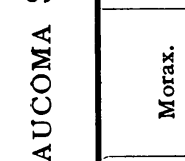 & 요 & $\begin{array}{l}0 \\
0 \\
0 \\
0 \\
n .\end{array}$ & ن் & 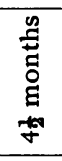 & 1 & 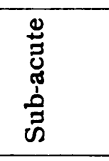 & 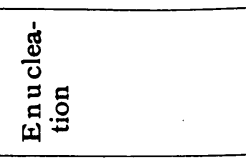 & 1 \\
\hline 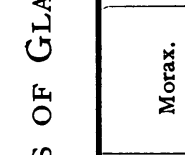 & เั & 苞 & ن & $\begin{array}{l}\tilde{z} \\
\vdots \\
\square\end{array}$ & 1 & 节 & 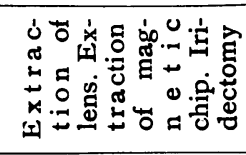 & 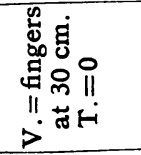 \\
\hline $\begin{array}{l}\stackrel{x}{\pi} \\
\stackrel{0}{\Sigma}\end{array}$ & 9 & 苂 & $\begin{array}{c}\dot{0} \\
\stackrel{0}{\bar{u}}\end{array}$ & 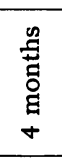 & 1 & 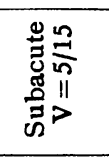 & 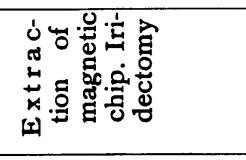 & 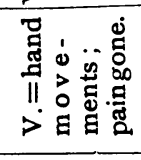 \\
\hline 聜 & $\begin{array}{c}\vdots \\
\vdots \\
\vdots \\
\vdots \\
\vdots\end{array}$ & $\begin{array}{c}\vdots \\
\vdots \\
\vdots \\
\vdots \\
\vdots \\
\vdots\end{array}$ & 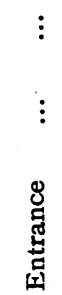 & 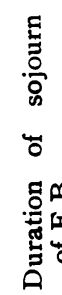 & 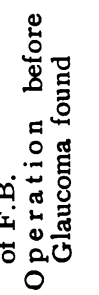 & 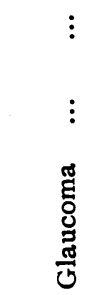 & 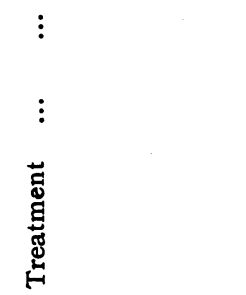 & $\begin{array}{c}\vdots \\
\vdots \\
\vdots \\
\vdots \\
\stackrel{\Xi}{3} \\
\stackrel{3}{*}\end{array}$ \\
\hline
\end{tabular}


established by extraction or by radioscopy, and the glaucomatous state has preceded all operative interference. There have been attacks of glaucoma, in which the tension, originally 40 to $60 \mathrm{~mm}$. Hg., had shot up to 60 and $80 \mathrm{~mm}$. with consequent congestion and pain; and others with lower degrees of tension, about 30 to $40 \mathrm{~mm}$. Hg., where attention was directed to the tension because of a poor visual result with a clear pupil. Miotics seem of little value in keeping down the tension in these cases. There was small likelihood of these cases being predisposed to glaucoma, as might be suggested, for they were all young, and in every case one eye only was affected. Morax says that the part played by contusion in his cases was quite negligible, as the smallness of the scleral wounds indicates; but in the notes of his cases, No. 1 had a rupture of choroid, with hæmorrhages about it, and a foreign body weighing 27 milligrammes; No. 3 showed the "fundus changes, pigmentary and atrophic, which accompany traumatic alterations of the choroid and retina," and in the enucleated eye was found a very small piece of stone, weight not stated; in two other cases the fundus appearances were either not made out or not recorded.

The foreign body need not be of iron to cause the glaucoma, and it may be aseptic and still cause tension, just as a dislocated lens may, although Morax does not desire to push this analogy too far. None of the cases showed signs of cyclitis, so that there was probably not any torpid affection of the ciliary body.

Treatment seems most unsatisfactory from the functional side, while it may relieve pain. One is driven to enucleation or evisceration, if the extraction of the foreign body, miotics, sclerecto-iridectomy, and anterior and posterior sclerotomies fail. Morax strongly advises careful observation of the tension in all cases of intra-ocular foreign bodies as a complement to radioscopy and radiography, and further calls for a more extended use in early cases of the electro-magnet.

His table includes several cases from the literature, as well as his own five now recorded. The most striking point is the bad result obtained in almost every case.

W. C. Souter.

(21) At the Ophthalmic Centre of the 14th Military Area, 3,915 wounded were treated up to December 31, 1916. Of this number there were 343 cases of lesions of the deep tunics of the eye, without disorganization of the eyeball, a percentage of 8:76. The authors exclude from this list lesions produced by intra-ocular foreign bodies, cases in which the vitreous is filled by blood and no view of the fundus is obtainable, and wounds of the anterior segment of the globe (iridodialysis with hyphæma, traumatic cataract, 'etc.) in which the existence of fundus lesions is conjectural. 
In 145 of the total number the impact of the projectile was upon the eyeball, choc direct. In 128 the impact was upon adjoining structures, choc indirect:-

The malar region was involved in 34 cases

The outer end of the eyebrow " , $\quad 28$,

The temporal region " " 24 "

The infra-orbital region " ", 22,

The frontal region " " 19 "

The mastoid region " " 1 case

In 22 cases the exact site of the wound could not be determined; in 24 cases there were multiple wounds. In 22 cases the ocular lesions were due to the passage of bullets through the facial structures; of these the greater number involved the temporal region, the outer margin of the orbit, the malar and superior maxillary bones.

The authors draw attention to instances of fundus lesions in men exposed to the explosion of a shell at a short distance, in whom no wound of the eyeball or surrounding structures is discoverable. Terrien has noted some cases of this kind and Rollet and Velter have had one such under observation. They attribute the choroidal lesion (rupture) to the force of the air concussion.

Although the diversity of the lesions observed renders it difficult to classify them, the authors have grouped their cases under the following headings:-

1. Detachment of retina of all grades, 43 cases.

2. Detachment with exudation, resulting in proliferating retinitis, or the formation of cicatricial bands, 37 cases.

3. Rupture of the choroid, 133 cases. The variation in the extent and position of the ruptures is in noticeable contrast to the usual crescentic lesions at the posterior pole, met with in the accidents of civil life.

4. Choroido-retinal hæmorrhage and resulting changes, 130 cases, of which 38 were examples of hæmorrhage in the macular area.

5. Concomitant lesions of the papilla. These have been noted in about one-third of the cases of rupture and hæmorrhage at the posterior pole. They have included simple hyperæmia of the papilla, well-marked papillitis, atrophy of the papilla in varying degree, and complete obliteration of the papilla.

The prognosis in cases such as those under consideration is naturally most uncertain. The lesions are slow in healing, and much time must elapse before the final stage is reached. In a certain number, however, in which the macula has not been irremediably damaged, a considerable and quite useful degree of .vision may be ultimately regained.

The paper is accompanied by a plate of six coloured drawings of choroido-retinal lesions.

J. B. LAWFORD. 
(22) Ourgaud reports a case in which, as the result of a shell wound, the lower fourth of the cornea was destroyed; the gap was occupied by iris; there was traumatic cataract.

The day following the wound the conjunctiva was divided at the limbus in the whole circumference, the jagged edges of the corneal wound were cauterized, the conjunctiva was drawn over the cornea and its edges were united by a transverse suture. Seven days later the stitches were removed, and the upper portion of the conjunctiva began to retract. Two weeks later the upper flap of conjunctiva was in its normal position. The lower part was firmly adherent to the margins of the wound, forming a large opaque patch over the inferior half of the cornea. This area protruded slightly, but in four months the prominence had entirely disappeared. The loss of corneal tissue appeared to be completely replaced. Tension normal. An upward iridectomy and extraction of the cataract were subsequently performed. The resulting vision was finger-counting at $30 \mathrm{~cm}$. with a $+10 \mathrm{D}$. lens.

J. B. LAWFORD.

\section{BOOK NOTICE}

Les Fractures de l'Orbite par Projectiles de Guerre. By Felix Lagrange, Professor in the Faculty of Medicine, Bordeaux. With 6 plates and 77 figures in the text. Paris: Masson et Cie. Price, 4 francs. 1917.

Messrs. Masson and Co. are issuing a series of "Précis de Médecine et de Chirurgie de Guerre." Eighteen volumes have already appeared and others are announced. They give an excellent account of the methods of French medicine and surgery for dealing with the disabilities produced by the war, concise, well written, and admirably illustrated. Professor Lagrange has contributed a volume on injuries of the orbit. His title is somewhat misleading, for a large proportion of his book deals with injuries of the eyeball itself, whether incidental to fractures of the orbit or not.

The first chapter is devoted to a short historical account of war injuries to the eye and neighbouring parts, ranging from Homer to a Madrid thesis of 1916. It occupies nine pages, cites a few French and German authors, and is the least satisfactory part of the book.

The second chapter contains a brief account of the anatomy of the orbit, the resistance of its base and walls to traumatism, the application of the laws of dynamics to the orbit, and its vulnerability.

The third chapter gives statistics derived from the Base Hospital to which Professor Lagrange is attached, and considers the general question of the ætiology of fractures of the orbit. One important 